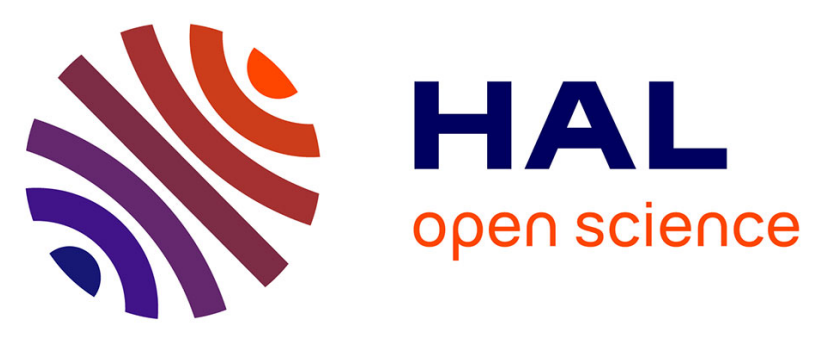

\title{
Surfactant Micelles Enable Metal-Free Spirocyclization of Keto-Ynamides and Access to Aza-Spiro Scaffolds in Aqueous Media
}

Frédéric Beltran, Andrea V Vela-Gonzalez, Tatiana Knaub, Marc Schmutz, Marie Pierre Krafft, Laurence Miesch

\section{To cite this version:}

Frédéric Beltran, Andrea V Vela-Gonzalez, Tatiana Knaub, Marc Schmutz, Marie Pierre Krafft, et al.. Surfactant Micelles Enable Metal-Free Spirocyclization of Keto-Ynamides and Access to Aza-Spiro Scaffolds in Aqueous Media. European Journal of Organic Chemistry, 2019, 2019 (41), pp.6989-6993. 10.1002/ejoc.201901441 . hal-02959120

\section{HAL Id: hal-02959120 \\ https://hal.science/hal-02959120}

Submitted on 6 Oct 2020

HAL is a multi-disciplinary open access archive for the deposit and dissemination of scientific research documents, whether they are published or not. The documents may come from teaching and research institutions in France or abroad, or from public or private research centers.
L'archive ouverte pluridisciplinaire HAL, est destinée au dépôt et à la diffusion de documents scientifiques de niveau recherche, publiés ou non, émanant des établissements d'enseignement et de recherche français ou étrangers, des laboratoires publics ou privés. 


\title{
Surfactant Micelles Enable Metal-Free Spirocyclization of Keto- Ynamides and Access to Aza-Spiro Scaffolds in Aqueous Media
}

\author{
Frédéric Beltran ${ }^{+}$, Andrea V. Vela-Gonzalez ${ }^{+}$, Tatiana Knaub ${ }^{++}$, Marc Schmutz, Marie Pierre Krafft ${ }^{\star}, b$ \\ and Laurence Miesch ${ }^{\star, a}$
}

\begin{abstract}
Micellar solutions of cetyltrimethylammonium bromide (CTAB) surfactant allow the spirocyclization of keto-ynamides in an aqueous medium without recourse to transition-metal catalysis, enabling access in water to naturally-occurring aza-spiro compounds with potential in drug discovery. The reaction was monitored by dynamic light scattering (DLS) and cryogenic transmission electron microscopy (cryo-TEM), which determined the morphology and change in size of the micelles before and after incorporation of the substrate and achievement of 5-endo-dig cyclization inside the micelles.
\end{abstract}

\section{Introduction}

Limiting the use of organic solvents in synthesis is currently an intensely pursued goal. ${ }^{[1]}$ Performing complex reactions in water is, however, limited by the poor solubility of most organic compounds. Micelle-forming surfactants can enable the solubilization of otherwise insoluble compounds. Metal-catalyzed reactions carried out in micellar systems have been extensively studied. ${ }^{[2]}$ In the recent years, the scope of reactions conducted in micellar systems has significantly broadened with, for example, the aerobic oxidation of aryl alkynes ${ }^{[3]}$ the nucleophilic aromatic substitution, ${ }^{[4]}$ the sulfonylation of polyfluoroarenes ${ }^{[5]}$ and the monofluorination of indoles. ${ }^{[6]}$ The use of micellar systems in the above-mentioned examples also limits the recourse to transition metal catalysts. These recent advances have made micelle-enabled reactions possible at an industrial scale with good reproducibility and low $E$ factor. ${ }^{[7]}$ In this blooming field it is however striking that, although the size and shape of the micelles were identified as key to achieve high levels of conversion, hence the concept of "designer" surfactant, ${ }^{[2 b]}$ no information appears to be available on the effect of the substrate on the morphology and size of the micelles during the reaction. To our knowledge, physical techniques, such as dynamic light scattering and electron

[a] Dr. L. Miesch, F. Beltran, T. Knaub ${ }^{++}$

Équipe Synthèse Organique et Phytochimie

Institut de Chimie, CNRS-UdS UMR 7177

4 rue Blaise Pascal, CS 90032, 67081 Strasbourg (France)

E-mail:Imiesch@unistra.fr

https://sophy.chimie.unistra.f

[b] Dr. M. P. Krafft, A. Vela Gonzalez, Dr. Marc Schmutz

University of Strasbourg

Institut Charles Sadron (CNRS)

23, rue du Loess, 67034 Strasbourg (France)

E-mail:krafft@unistra.fr

http://sams.ics-cnrs.unistra.fr/recherche/auto-assemblages-fluores/

[+] These authors contributed equally to this work.

[++] TK achieved experiments in both Laboratories, the Équipe de

Synthèse Organique et Phytochimie and the Institut Charles Sadron. microscopy, have so far only been applied to the characterization of the empty micelles. ${ }^{[5]}$ Depending on its location in the micelle, whether in the hydrophobic core or in the polar zone formed by the surfactant polar heads, the substrate can differently impact the size and shape of the micelle, and hence, the outcome of the reaction. A large group of bioactive compounds possesses a spirocyclic system that is usually part of a more complex ring system. ${ }^{[8,9]}$ We reported recently the spontaneous spirocyclization of keto-sulfonamides via ynamides in a one-pot process ${ }^{[10]}$ (Scheme 1, reaction a). Furthermore, quaternary ammonium salts allowed the spirocyclization of nonactivated keto-ynamides ${ }^{[11]}$ (Scheme 1 , reaction b) All these reactions were conducted in classical organic solvents.

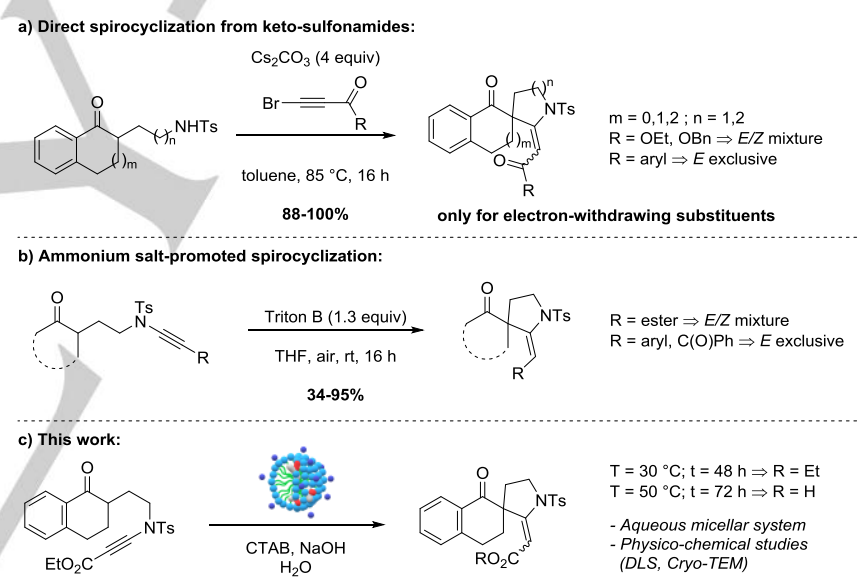

Scheme 1. Spirocyclization of keto-ynamides.

In the present work, we report the first spirocyclization of a keto-ynamide in micelles of cetyltrimethylammonium bromide (CTAB) in the absence of any transition metal catalyst. We proved directly by dynamic light scattering (DLS) and cryogenic electron microscopy (cryo-TEM) that the substrate is encapsulated in the micelles after deprotonation, and that spirocyclization occurs subsequently in the inner core of the micelles (Scheme 1, reaction c).

Reports on the synthesis of spiro compounds in water are scarce. The only example we are aware of uses sodium stearate in a Lewis base surfactant-combined catalysis in a threecomponent one-pot reaction. ${ }^{[12]}$ This synthesis led to spirooxindole derivatives in aqueous micellar media. However, this method is limited to the use of isatin, malonitrile and 1,3dicarbonyl compounds. Although the quaternary center is present in the target compound, the pyranic structure of the second spiro ring thus created cannot allow direct access to natural compounds. 
Here, we explored the 5-endo-dig cyclization starting from a keto-ynamide solubilized in an aqueous micellar system, while monitoring the incorporation of the substrate in the micelles before the onset of the reaction, and eventually the presence of the final product in the micelles, using DLS and cryo-TEM.

\section{Results and Discussion}

We first prepared micellar solutions of a variety of surfactants, including anionic ones (i.e. sodium dodecylsulfate, SDS) and neutral ones (i.e. Tween 40, a polyethoxylated sorbitan esterified by fatty acids; Pluronic-F68, an amphiphilic block copolymer; and TPGS-750-M, a diester comprising racemic a-tocopherol, MPEG-750, and succinic acid), in the presence of one equivalent of a base $(t \mathrm{BuONa})$. In these conditions no spirocyclization was observed and the starting material was fully recovered (Supporting Information, Table S1). Then, having recently used quaternary ammonium salts to perform spirocyclization in organic solvents, ${ }^{[11]}$ we investigated the spirocyclization of the keto-ynamide 1 within the organic core of micelles of cetyltrimethylammonium bromide (CTAB) dispersed in water, and this without recourse to a transition metal (Scheme 2). Keto-ynamide 1 was prepared via copper catalyzed $\mathrm{N}$-alkynylation of the corresponding tosylsulfonamide using Hsung's procedure. ${ }^{[13]}$
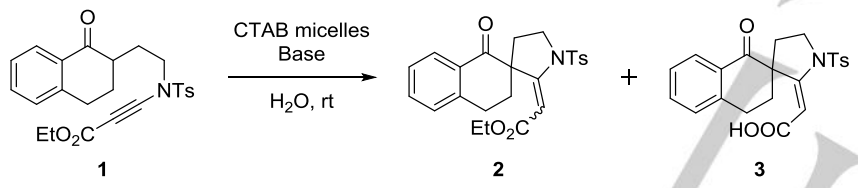

Scheme 2. Synthesis of aza-spiro compounds in aqueous micellar solutions.

We found that the 5-endo-dig cyclization of keto-ynamide 1 can be successfully achieved in aqueous micellar solutions of CTAB using $\mathrm{NaOH}$ as the base. Micelle morphology and size were determined before and after introduction of the substrate, and after completion of reaction.

Solutions of CTAB alone $\left(0.03 \mathrm{~mol} \mathrm{~L}^{-1}\right)$ in aqueous $\mathrm{NaOH}$ $\left(0.03 \mathrm{~mol} \mathrm{~L}^{-1}\right)$ are transparent and consist of a homogenous population of spherical micelles, as evidenced by cryo-TEM, the spherical micelles are highlighted with arrows, the core of the micelles are seen as black dots as reported earlier ${ }^{[14]}$ (Fig. 1a). DLS analysis of micellar CTAB solutions were performed after adding a $\mathrm{NaCl}$ solution $\left(0.8 \mathrm{~mol} \mathrm{~L}^{-1}\right)$ in order to screen the electrostatic interactions. Figure $1 \mathrm{~b}$ shows the variation of the autocorrelation function, the fast decay of which signals the presence of small circular micelles, in agreement with earlier reports. ${ }^{[15]}$ The deduced size distribution exhibits a predominant peak centered at $\sim 3.6 \mathrm{~nm}$ (polydispersity index 16\%).
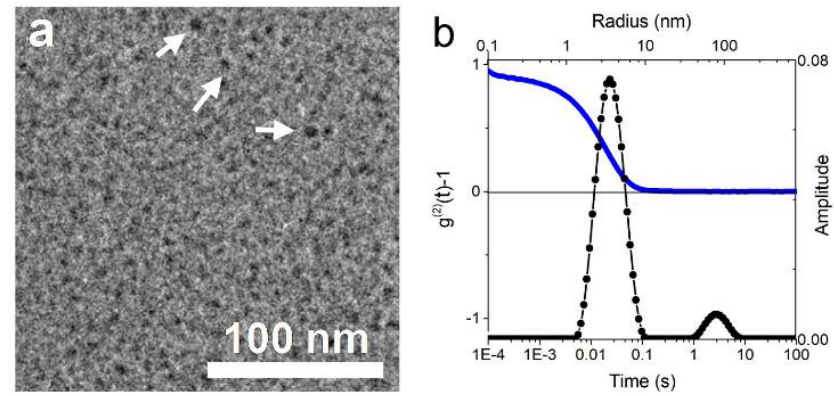

Figure 1. a) cryo-TEM image (the arrows indicate the micelle cores seen as black dots), and b) DLS profile of the micelles formed in solutions of CTAB $\left(0.03 \mathrm{~mol} \mathrm{~L}^{-1}\right)$ in aqueous $\mathrm{NaCl}\left(0.8 \mathrm{~mol} \mathrm{~L}^{-1}\right)$, showing the decay of the autocorrelation function over time (blue) and the variation of the amplitude versus the hydrodynamic radius (black).

We then incorporated the keto-ynamide $\mathbf{1}$ in an aqueous dispersion of CTAB micelles at $30^{\circ} \mathrm{C}$. The substrate/surfactant ratio was set to $1: 25$, meaning that $\sim 6$ molecules of 1 are solubilized in one $C T A B$ micelle, knowing that the typical aggregation number in $\mathrm{CTAB}$ micelles is around 137 at $30^{\circ} \mathrm{C} .^{[16]}$ The payload in substrate was chosen relatively low in order to facilitate its incorporation in the organic core of the micelles. The addition of 1 resulted in an opacification of the initially transparent micellar solution, indicating that the substrate is not immediately solubilized. This was further supported by cryo-TEM experiments that show micron-size crystals coexisting with CTAB micelles (Fig. 2a) and by absorbance measurements (Fig. $2 b)$. The incorporation of the keto-ynamide in the micelles is complete after $2 \mathrm{~h}$, as monitored by light absorbance experiments that shows that the medium recovers its transparency. Cryo-TEM (Fig. 2c) and DLS (Fig. 2d) experiments show that the CTAB micelles $(\sim 8.2 \mathrm{~nm}$ in radius, polydispersivity index $25 \%$ ) are loaded with keto-ynamide.
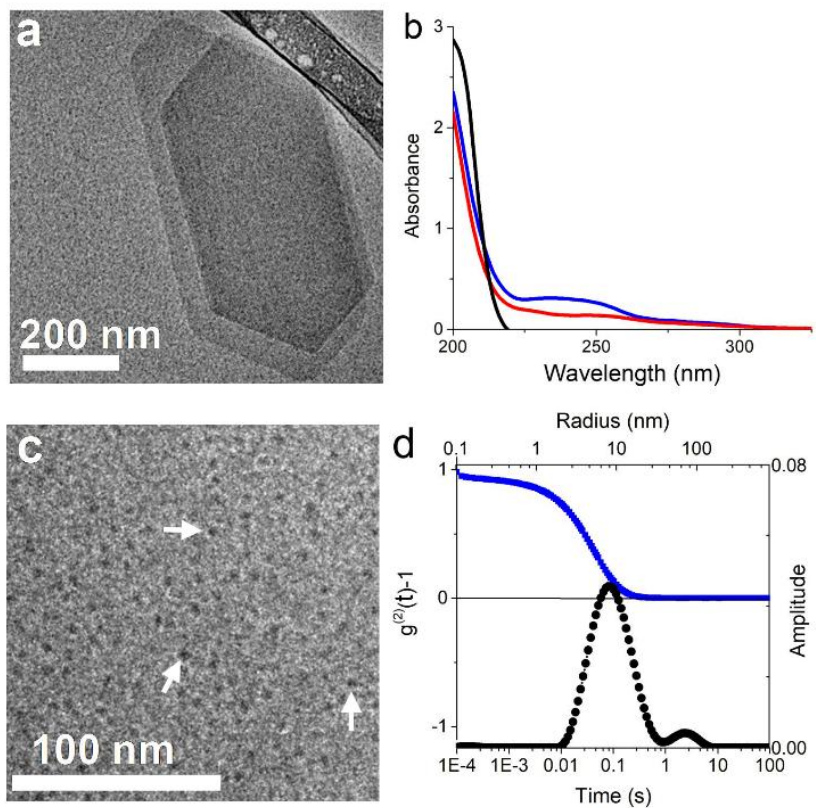
Figure 2. a) cryo-TEM image taken immediately after incorporation of the keto-ynamide in the micellar solution showing non-solubilized crystals of substrate. b) Absorbance spectra of CTAB micelles in water (black), CTAB micelles loaded with keto-ynamide (blue), CTAB micelles containing the azaspiro compound (after $48 \mathrm{~h}$, red). c) Cryo-TEM image, and d) DLS of CTAB micelles $\left(0.03 \mathrm{~mol} \mathrm{~L}^{-1}\right.$ in $\left.0.8 \mathrm{~mol} \mathrm{~L}^{-1} \mathrm{NaCl}\right)$ loaded with the keto-ynamide substrate showing the autocorrelation function decay (blue) and the variation of amplitude versus hydrodynamic radius (black) after $4 \mathrm{~h}$.

After $48 \mathrm{~h}$ of stirring at $30^{\circ} \mathrm{C}$, the reaction medium is transparent and homogenous. The work-up of the reaction mixture led to the spiro ester 2 (as an $E / Z$ mixture) in $79 \%$ yield, along with $E$ spiro acid 3 (18\%) (Table 1, entry 1). It should be noticed that an exclusive $E$ configuration of the double bond for the acid was obtained, likely due to a faster saponification of the $E$-isomer favored by intramolecular hydrogen bonding between the carbonyl group and carboxy function of the enamide. Importantly, no reaction was observed in the absence of CTAB; the keto-ynamide substrate was totally recovered (Table 1, entry 2 ), meaning that the micelles are mandatory for the reaction to occur. Reducing the reaction time from $48 \mathrm{~h}$ to $16 \mathrm{~h}$ led to incomplete reaction: $30 \%$ of the starting material was recovered (Table 1, entry 3 ). The ester/acid ratio (4:1) remains constant. In this case, the reaction medium was still turbid, suggesting that the keto-ynamide was not totally incorporated in the micelles, as confirmed by micelle sizing (Supporting Information, Figure S1). Likewise, decreasing the concentration of CTAB to 10 equivalents also reduces the conversion ( $50 \%$ only), while the ester/acid ratio remains constant (4:1) (Table 1, entry 4). Changing the base from $\mathrm{NaOH}$ to $\mathrm{LiOH}$ or $\mathrm{KOH}$ did not improve the results (Table 1, entries 5,6 ). It is noteworthy that even if the surfactant Triton B leads to spirocycle 2 in the $\mathrm{THF} / \mathrm{H}_{2} \mathrm{O}$ mixture $(100 / 1.6),{ }^{[11]}$ Triton $B$ only leads to the starting material along with hydrated ynamide (20\%) when the synthesis is performed in water (table 1, entry 7). A gram scale experiment with $\mathrm{CTAB} / \mathrm{NaOH}$ was performed leading to spirocycle 2 without erosion of the yield.

Table 1. Reactivity of the keto-ynamide $\mathbf{1}$ in micellar solutions of cetyltrimethylammonium surfactants CTAB. ${ }^{[a]}$

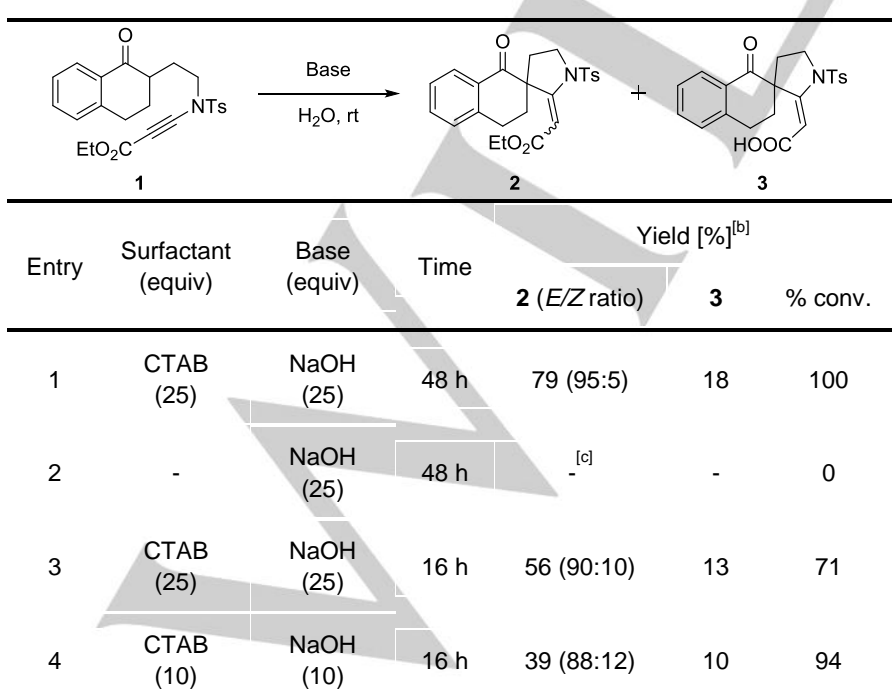

\begin{tabular}{lcccccc}
5 & CTAB & LiOH & $16 \mathrm{~h}$ & $38(88: 12)$ & - & 48 \\
& $(1.3)$ & $(1.3)$ & & & & \\
6 & CTAB & KOH & & & \\
& $(1.3)$ & $(1.3)$ & $16 \mathrm{~h}$ & $37(88: 12)$ & - & 57 \\
7 & - & Triton B & $48 \mathrm{~h}$ & - & - & $20^{[\mathrm{d}]}$ \\
\hline
\end{tabular}

[a] Reactions were conducted at $30^{\circ} \mathrm{C}$. [b] Yield of isolated compounds. [c] Starting material is totally recovered. [d] $20 \%$ hydrated ynamide was obtained along with starting material.

We characterized the micellar solution directly as mixture at the end of the reaction in the conditions that lead to $79 \%$ of spiro ester 2 (Table 1 entry 1). Figure 3a shows a cryo-TEM image of the reaction mixture after $48 \mathrm{~h}$, when the work-up was initiated. It shows that this mixture is homogenous (see also larger field images in Supporting Information, Fig. S2) and only contains small spherical micelles. No crystals or aggregates were observed, which means that all the aza-spiro compound is located in the micelles. DLS measured at different angles confirms the homogeneity of the reaction mixture and shows a fast decay of the autocorrelation function with time, reflecting the presence of small spherical micelles $\sim 3.9 \mathrm{~nm}$ in radius (polydispersity index 10\%).
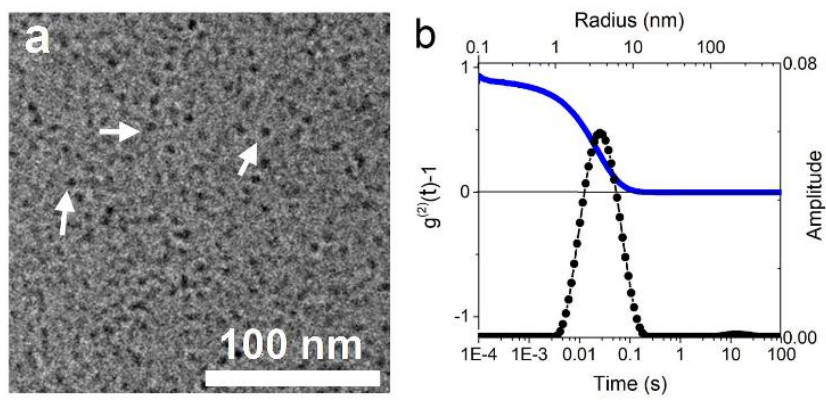

Figure 3. a) Cryo-TEM image (the arrows indicate the micelle cores seen as black dots), and b) DLS of CTAB micelles $\left(0.03 \mathrm{~mol} \mathrm{~L}^{-1}\right.$ in $\left.0.8 \mathrm{~mol} \mathrm{~L}^{-1} \mathrm{NaCl}\right)$ containing the aza-spiro compound after completion of the reaction. In b) autocorrelation function decay over time (blue) and variation of the amplitude versus the hydrodynamic radius (black).

As the micellar conditions used led to a mixture of three compounds, we attempted to convert the $E / Z$ mixture of spiro ester 2 into E-spiro-acid exclusively. Whereas classical saponification conditions in organic solvents (i.e. $\mathrm{NaOH} / \mathrm{MeOH}$, $\mathrm{LiOH} . \mathrm{H}_{2} \mathrm{O} / \mathrm{THF} / \mathrm{H}_{2} \mathrm{O}, \mathrm{KOH} / \mathrm{DMSO}$ ) did not provide acid 3 , saponification conducted within the micellar system at $50^{\circ} \mathrm{C}$ led to the desired E-configurated acid 3 in $75 \%$ yield (Scheme 3 ), thus emphasizing the scope of the micellar reaction. To the best of our knowledge saponification of enamides substituted with an ester function has been reported only once in a specific case of methyleneisoindolinones. ${ }^{[17]}$ 


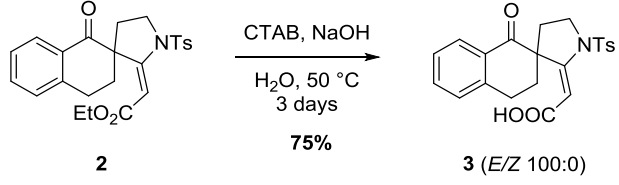

Scheme 3. Saponification of the spiro-enamide within CTAB micelles.

We propose the following mechanism to explain the cryoTEM and DLS data (Scheme 4). Keto-ynamide $\mathbf{1}$ is deprotonated outside the micelles (1.a). The surfactant selected, CTAB, consists of an amphiphilic cation and a bromide counterion. The CTAB micelles have positive surface charges and loosely bound $\mathrm{Br}^{-}$ions (Scheme 4a). ${ }^{[18]}$ This arrangement promotes interactions with the negatively charged keto-ynamide substrate, which facilitate its incorporation in the micelles. The electronic interactions between the polar heads of CTAB in the micelles and the flexible side chain of the keto-ynamide, likely contribute to a preferred localization of the substrate in the vicinity of the polar heads (Scheme $4 \mathrm{~b}$ ), leading to the observed significant enlargement of the micelles (from $\sim 3.6 \mathrm{~nm}$ to $\sim 8.2 \mathrm{~nm}$ in radius). The confinement of the enolate enables the reaction to take place, and its orientation, with the negatively charged tertiary enamide oriented toward the positively charged heads of the micelles, favors the formation of the $E$ configurated enamide. This results in higher $E / Z$ selectivity (95:5) as compared to that obtained when the reaction is performed in organic solvent $(77: 23) .^{[11]}$ a

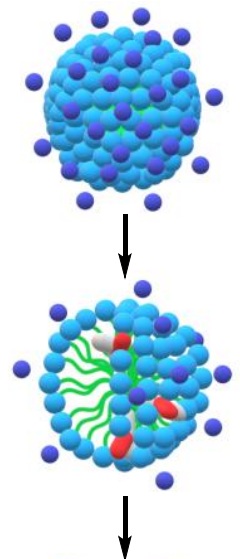

C

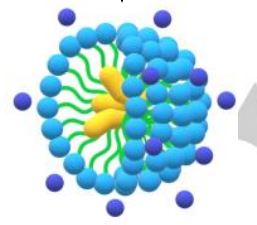

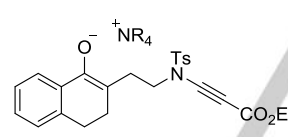

1.a

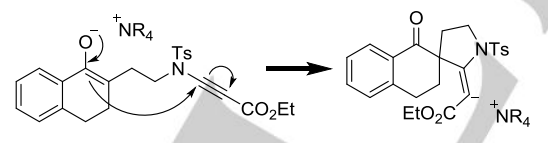

Scheme 4.a Schematic representation of spherical CTAB micelles (light blue: CTAB polar heads, dark blue: $\mathrm{Br}$ ions, green: CTAB aliphatic chains). The negatively charged deprotonated keto-ynamide substrate 1.a interacts electrostatically with the positively charged surface of CTAB micelles, leading to its incorporation at the interface (4.b). As the reaction proceeds, ketoynamide 1.a is converted into the neutral aza-spiro final compound 2, which is preferentially located among the fatty chains that form the core of the micelles (4.c).
After protonation at the interface by water molecules, the aza-spiro 2 is no longer charged and exhibits a more compact structure due to its more rigid tridimensional conformation. As a consequence, the compound is preferentially located in the hydrophobic core of the micelle, thus accounting for the eventual decrease of the micelle radius to $-3.9 \mathrm{~nm}$ (Scheme 4c). Moreover, the confinement of the substrate in the micelle and the trapping of the hemiacetal at the interface is also advantageous for the saponification of the spiro-compound. The fact that saponification does not occur in organic solvents thus further supports the proposed mechanism.

\section{Conclusion}

To sum up, we found that the spiro-cyclization of ketoynamide 1 can only occur in water when performed in micelles of $\mathrm{CTAB}$ without recourse to metal catalysis. Aza-spiro esters $E / Z(95: 5)$ and the corresponding spiro-acid $(100 \% E)$ were obtained with good yields. The esters can be converted within the micelles in the pure $E$ acid with $75 \%$ yield. These compounds possess the aza-spirocyclic framework found in naturally occurring compounds that have powerful bioactivity, and in several synthetic drugs. To our knowledge, this is the first time that such compounds are synthesized in aqueous media using micelles as nanoreactors. Cryo-TEM and DLS proved the encapsulation of the substrate and subsequent spirocyclization in the CTAB micelles. The changes in micelle size during reaction, provided insights on the interactions between the substrate and the micelles as well as on the reaction mechanism.

\section{Experimental Section}

See the Supporting Information for experimental details.

\section{Acknowledgements}

FB thanks the Ministère de la Recherche et de la Technologie (MRT) and AV thanks CONACYT (scholarship \#459202) for their Ph.D scholarships. The authors are also grateful to the University of Strasbourg (travel grant for AV), the CNRS and ANR. The electron microscopy platform of the Institut Charles Sadron (Dr. M. Schmutz) is acknowledged, and Dr. F. Schosseler for help in the dynamic light scattering measurements.

Keywords: Ynamides - Spirocyclization - Ammonium surfactants (Cationic surfactants) • Micellar solution • Micellar catalysis - Dynamic light scattering • Cryogenic transmission electron microscopy.

[1] B. H. Lipshutz, S. Ghorai, Green Chem. 2014, 16, 3660-3679.

[2] a) B. H. Lipshutz, S. Ghorai, Aldrichimica Acta 2008, 41, 59-72; b) B. H. Lipshutz, S. Ghorai, A. R. Abela, R. Moser, T. Nishikata, C. Duplais, A Krasovskiy, J. Org. Chem. 2011, 76, 4379-4391; c) G. L. Sorella, G. Strukul, A. Scarso, Green Chem. 2015, 17, 644-683; d) S. Handa, B. 
Jin, P. P. Bora, Y. Wang, X. Zhang, F. Gallou, J. Reilly, B. H Lipshutz, ACS Catal. 2019, 9, 2423-2431; e) M. Bihani, P. P. Bora, M. Nachtegaal, J. B. Jasinski, S. Plummer, F. Gallou, S. Handa, ACS Catal. 2019, 9, 7520-7526.

[3] S. Handa, J. Fennewald, B. H. Lipshutz, Angew. Chem. Int. Ed. 2014, 53, 3432-3435.

[4] N. Isley, R. Linstadt, S. Kelly, F. Gallou, B. Lipshutz, Org. Lett. 2015, 17, 4734-4737.

[5] J. Smith, T. Ansari, M. Andersson, D. Yadagiri, F. Ibrahim, S. Liang, G. Hammond, F. Gallou, S. Handa, Green Chem. 2018, 20, 1784-1790.

[6] P. P. Bora, M. Bihani, S. Plummer, F. Gallou, S. Handa, ChemSusChem. 2019, 12, 3037-3042.

[7] M. Parmentier, C. M. Gabriel, P. Guo, N. A. Isley, J. Zhou, F. Gallou, , Curr. Opin. Green Sustainable Chem. 2017, 7, 13-17.

[8] T. M. Williams, C. S. Burgey, T. J. Tucker, C. A. Stump, I. M. Bell, Carboxamide spirolactam CGRP receptor antagonists, 2006, WO2006/031606A2.

[9] P. Y. Ng, H. Davis, K. W. Bair, D. S. Millan, A. Rudnitskaya, X. Zheng, B. Han, N. Barczak, D. Jr. Lancia, 3-spiro-7-hydroxamic acid tetralins as HDAC Inhibitors, 2016, WO2016/168660A1.
[10] F. Beltran, I. Fabre, I. Ciofini, L. Miesch, Org. Lett. 2017, 19, 5042-5045.

[11] F. Beltran, L. Andna, L. Miesch, Org. Chem. Front. 2019, 6, 373-376.

[12] L.-M. Wang, N. Jiao, J. Qiu, J.-J. Yu, J.-Q. Liu, F.-L. Guo, Y. Liu, Tetrahedron 2010, 66, 339-343.

[13] Y. Zhang, R. Hsung, M. Tracey, K. Kurtz, E. Vera, Org. Lett. 2004, 6, 1151-1154.

[14] Z. Lin, J. J. Cai, L.E. Scriven, H.T. Davis. J. Phys. Chem. 1994, 98, 23, 5984-5993.

[15] R. Dorshow, J. Briggs, C. A. Bunton, D. F. Nicoll, J. Phys. Chem. 1982, 86, 2388-2395.

[16] S. Anachkov, K. Danov, E. Basheva, P. Kralchevsky, K. Ananthapadmanabhan, Adv. Colloid Interface Sci. 2012, 183-184, 55 67.

[17] M. C. Reddy, M. Jeganmohan, Org. Lett. 2014, 16, 4866-4869.

[18] B. Lindman, G. Lindblom, H. Wennerstrom, N.-O. Persson, H. Gustavsson, A. Khan, in Magnetic Resonance in Colloid and Interface Science, J. P. Fraissard, H. A. Resing (eds.). NATO Advanced Studies Institutes Series. Reidel Publ., Dordrecht. 1980, 307-320. 


\section{Entry for the Table of Contents}

Layout 2:

\section{COMMUNICATION}

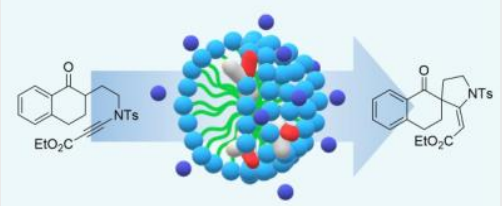

Naturally-occurring aza-spiro scaffolds are synthesized in aqueous micellar solutions of a cationic surfactant without metal catalysis. Dynamic light scattering and cryogenic transmission electron microscopy monitoring revealed the incorporation of the substrate and the presence of the reaction products in the micelles.

\section{Aqueous Micellar System}

F. Beltran, A.V. Vela-Gonzalez, T. Knaub, M. Schmutz, M.P. Krafft ${ }^{\star}$ and L. Miesch* $^{*}$

Page No. - Page No.

Surfactant Micelles Enable Metal-Free Spirocyclization of Keto-Ynamides and Access to Aza-Spiro Scaffolds in Aqueous Media 